revista ANTHROPOLÓGICAS

Ano 22, 29(1):57-83, 2018

\title{
Itacoatiaras do Ingá: As diferentes 'escritas' no imaginário da pedra das águas
}

Thais Catoira ${ }^{a}$

Carlos Xavier de Azevedo Netto ${ }^{\mathrm{b}}$

O presente artigo apresenta uma análise a respeito de algumas produções científicas, literárias, e artísticas que se referem às Itacoatiaras do Ingá. Assim, pode-se perceber através de diferentes perspectivas, abordagens e significações a respeito deste patrimônio arqueológico. Compreendendo que o conceito de patrimônio cultural deve assumir o sentido de que possibilita diversas dimensões significativas, que envolvem questões socioculturais e políticas, em suas diferentes formas, isso nos permitiu observar a partir de diferentes documentos, uma diversidade de interpretações e proposições, que ao mesmo tempo que podem criar obstáculos no que tange a educação patrimonial, ou em relação às informações científicas já encontradas. Ao mesmo tempo, podem encontrar ressonância nas lendas e mitos locais. Mas de todo modo, fazem com que esse patrimônio permaneça ativo na memória da comunidade local e, potencialmente da sociedade como um todo, através de representações, criando elementos que podem colaborar no processo de preservação deste patrimônio.

Pedra do Ingá; Patrimonialização; Preservação patrimonial; Memória.

O presente artigo apresenta uma análise a respeito de algumas produções científicas, literárias, e artísticas que se referem às itacoatia-

a Doutoranda em Ciência da Informação no Programa de Pós-Graduação em Ciência da Informação (UFPB), Bolsista CAPES'. Email: thaiscatoira.ufp@gmail.com.

b Professor Associado IV (DCI/UFPB), Vice-coordenador do Programa de Pós-Graduação em Ciência da Informação - PPGCI/UFPB. Email: xaviernetto@gmail.com. 
ras do Ingá. A Pedra do Ingá como é conhecida, fica localizada no município de Ingá no agreste paraibano. Assim, pode-se perceber através de diferentes perspectivas e abordagens uma gama diversa de significações a respeito deste patrimônio arqueológico. Leva-se em consideração que alguns pesquisadores já identificaram as variadas proposições interpretativas que giram em torno das itacoatiaras da Pedra do Ingá,

"A origem das inscrições é ainda desconhecida, mas produto de culturas indígenas que habitaram a região, e pela sua complexidade e mistério existem diferentes teorias e mitos que rodeiam a pedra e a origem das gravuras. Mitos populares falam a respeito de tesouros escondidos no interior da pedra que nunca foram encontrados. A respeito das insculturas, alguns pesquisadores que visitaram a região atribuem as gravuras a aborígines que lá viviam. Já os ufanistas atribuem a autoria a extraterrestres que confeccionaram as pedras através de raio laser" (Machado et al. 2012:177).

Essa diversidade de interpretações e proposições, ao mesmo tempo que podem apresentar distorções quando confrontadas às informações científicas já encontradas, no que tange a educação patrimonial, podem encontrar ressonância nas lendas e mitos locais. Mas de todo modo, fazer com que esse patrimônio permaneça ativo na memória da comunidade local e da sociedade como um todo, permite através dessas representações, elementos que podem colaborar no processo de preservação deste patrimônio.

Em relação ao conceito de patrimônio que se adota para este trabalho, perpassa a noção como categoria de pensamento (Gonçalves 2003), de modo a possibilitar o sentido de diversas dimensões significativas, que contém questões socioculturais e políticas, em suas diferentes formas, elementos essenciais para o funcionamento dos grupos humanos. Neste sentido, deve-se ultrapassar a dicotomia material e imaterial que por vezes parece ser uma característica para determinar as tipologias dos patrimônios, e perceber que ambos operam em uma materialidade inserida nos jogos de poder e interesses culturais e políticos, próprio das sociedades humanas, no qual se determina o que vai ser consagrado enquanto elemento representativo daquele grupo, 
ou por vezes aquilo que se coloca como obsoleto e deve ser deixado de lado (Miller 2013).

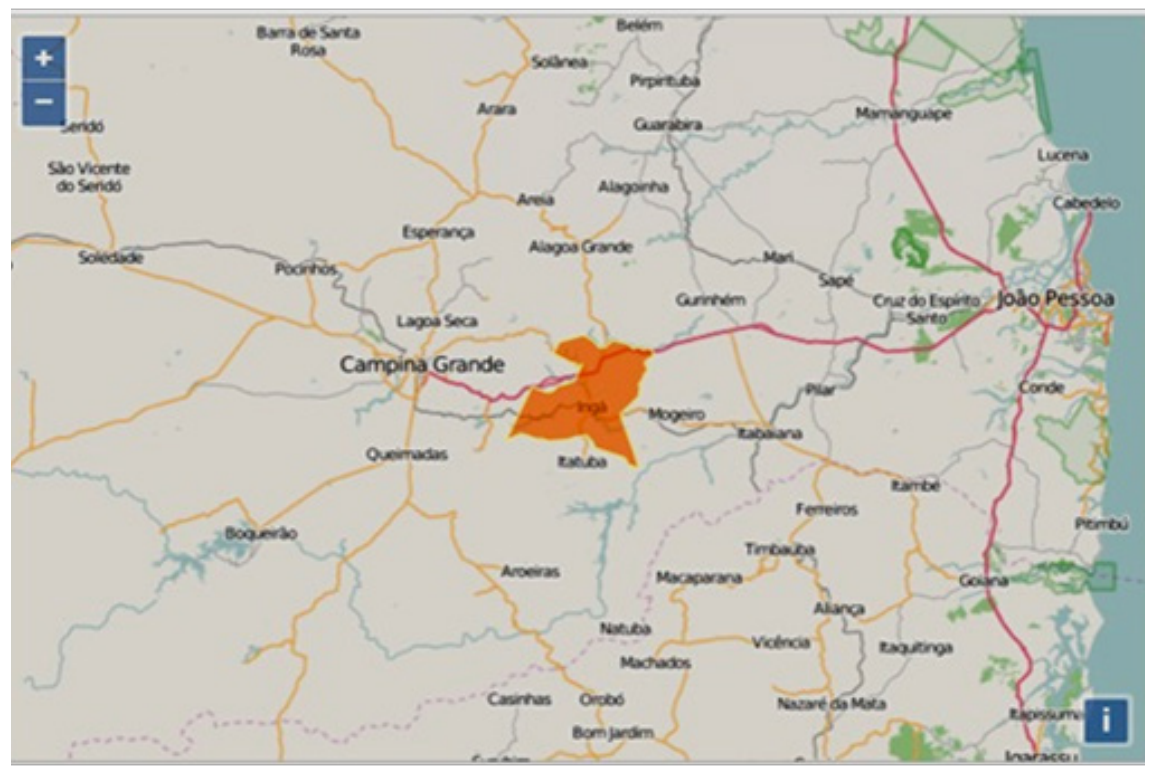

Imagem 01. Localização de Ingá/PB. Fonte: IBGE, 2016.

As memórias da comunidade que remetem a este patrimônio arqueológico trazem estórias de seus antepassados, os 'mais velhos', de modo que "reconhece a fala não apenas como um meio de comunicação diária, mas também como um meio de preservação da sabedoria dos ancestrais, venerada no que poderíamos chamar elocuções-chave, isto é, a tradição oral" (Vansina 2010:141). Esses testemunhos, fragmentados, são passados de geração a geração, por vezes ganhando novas roupagens, mas que ainda assim, se materializam através dos sentidos e das percepções daqueles que habitam o entorno desse sítio.

Por meio de informações arqueológicas sobre este patrimônio é possível compreender o porquê deste bem patrimonial ser considera- 
do tão importante para a memória cultural brasileira, conforme salienta Lopes \& Lage, "A Pedra do Ingá é um dos sítios arqueológicos mais importantes do Brasil e o mais extraordinário do Estado da Paraíba, em função da expressiva arte rupestre nele presente" (2013:01). As autoras acima citadas, apresentam o resultado de uma ação de prospecção e sondagem realizada em 2013, numa parceria entre o Instituto do Patrimônio Histórico e Artístico Nacional - IPHAN com o Núcleo de Antropologia Pré-Histórica da Universidade Federal do Piauí.

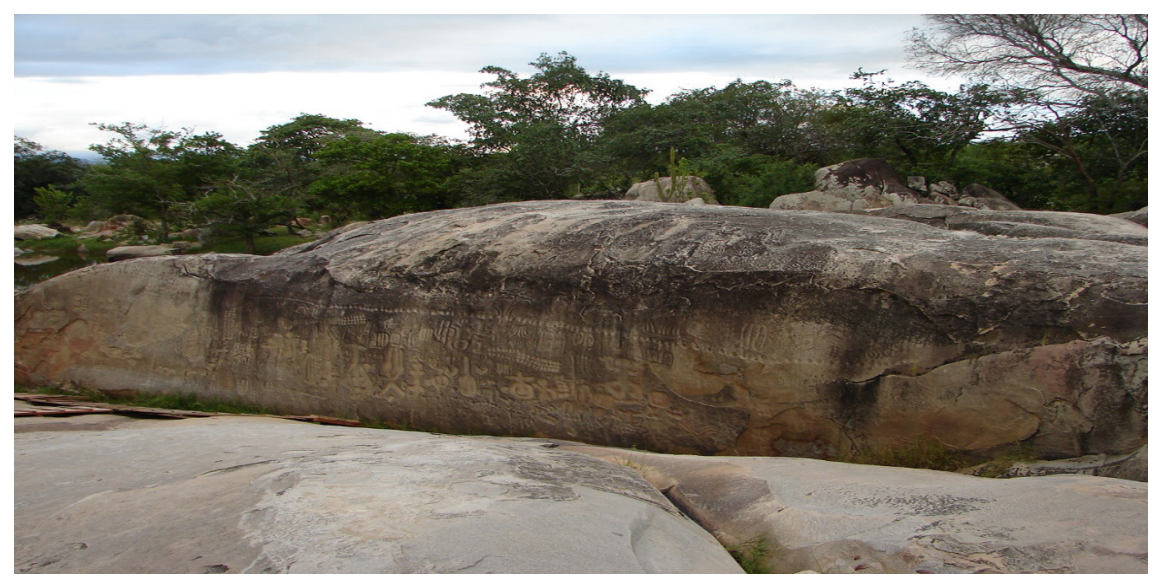

Imagem 02. Foto das inscrições da Pedra do Ingá. Fonte: Acervo Pessoal, 2010.

$\mathrm{Na}$ análise química dos sedimentos arqueológicos, buscando o teor de fósforo inorgânico, que ajuda a identificar possíveis vestígios de atividade humana, confirmaram que o "ambiente não propício a conservação de vestígios ósseos", uma vez que o local recebe quantidade significativa de água, nos momentos de cheia do rio Bacamarte. E Lopes \& Lage ainda observam que, "Os resultados obtidos para fósforo inorgânico juntamente com o material arqueológico encontrado no sítio ajudam a reforçar o fato da área ter sido ocupada por grupos humanos pré-históricos na região" (2013:03). 


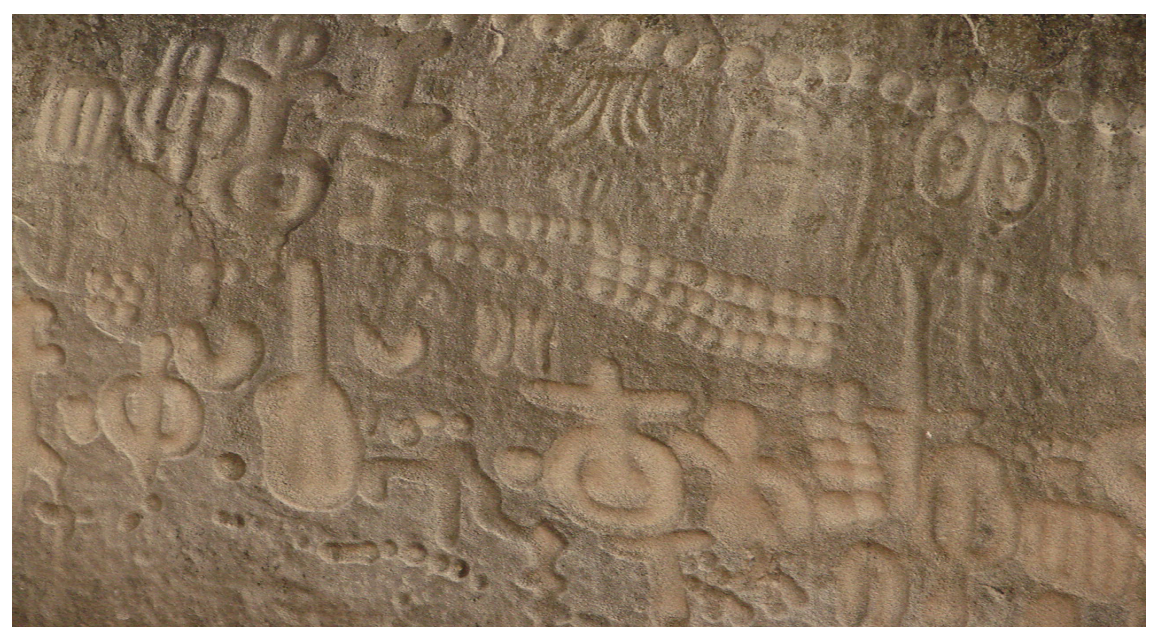

Imagem 03. Detalhe das gravações de Ingá. Fonte: Acervo Pessoal, 2010.

\section{Patrimonialização da Pedra do Ingá}

A etimologia da palavra Ingá vem do termo indígena tupi, que significa cheio d'água, ensopado. Provavelmente essa concepção advinda do fruto da árvore ingazeiro, que possui uma polpa bastante úmida e aquosa (IBGE, 2016). Tal espécie de árvore, natural do Brasil, encontrada em regiões de Bahia, Sergipe, Alagoas, Pernambuco e Paraíba (Carvalho 2006), acompanhava assim, toda a margem do rio Bacamarte, que atravessa a Pedra do Ingá, oferecendo sombra e frutos.

Em relação a fundação da cidade $^{1}$ do Ingá, esta estaria ligada a fazendas de exploração, agrícola e pecuarista, que deram início ao povoamento local. O município de Ingá está localizado a $107 \mathrm{~km}$ de distância da capital paraibana, conforme imagem 01 .

A Pedra do Ingá ou Itacoatiaras do Ingá, localizada na Fazenda Pedra Lavrada, cerca de 5,5km da cidade de Ingá, configura-se no agreste paraibano, (Brito 2008, 2010; Figueiredo \& Silva 2009), entrelaçando sua vegetação entre mata atlântica e caatinga (IBGE 2016). A Pedra do Ingá possui gravuras rupestres esculpidas em baixo relevo, conforme 
pode ser observado nas imagens 02 e 03 , além de outras inscrições marginalizadas por estarem mais distantes dos conjuntos principais, de modo que,

"Sua mais importante peça é a formação rochosa conhecida como Pedra do Ingá, que possui 16 dos seus 24 metros de extensão coberto de inscrições insculpidas, além de outras diversas espalhadas por todo o sítio" (Machado et al 2012:177).

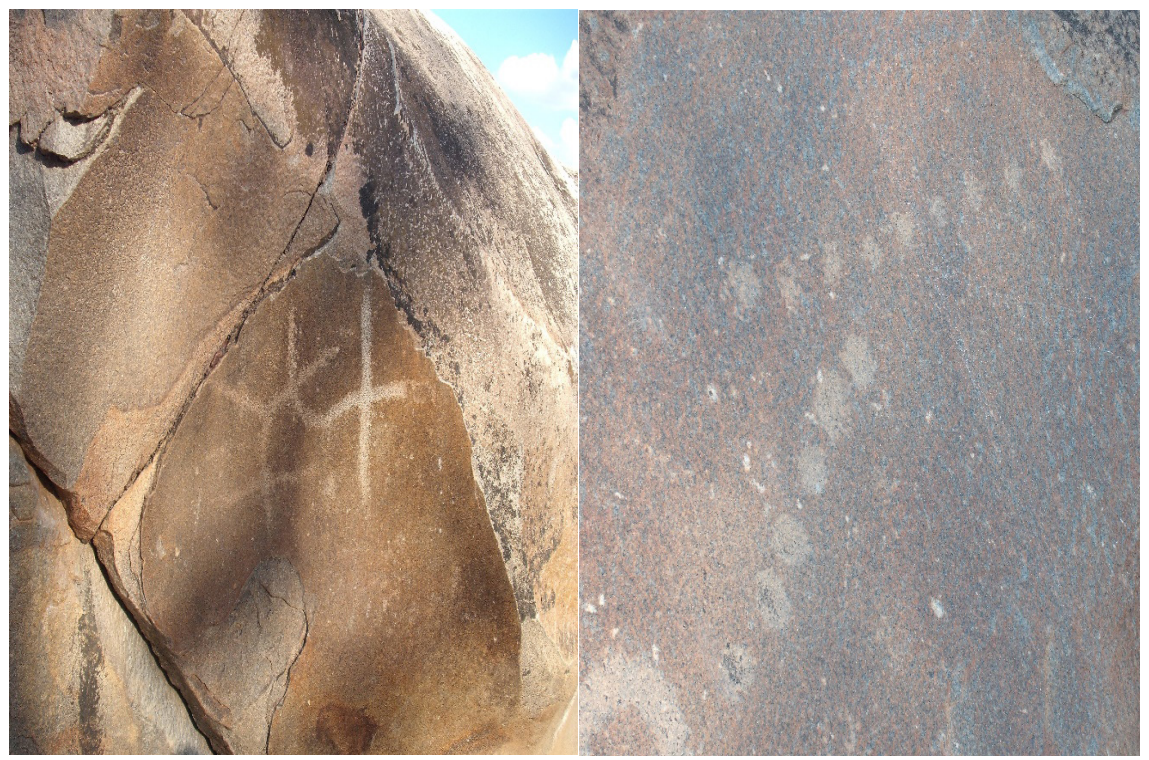

Imagem 04 - Dois exemplos de gravações com técnicas e formas diferentes, localizadas na face voltada ao rio. Fonte: Arquivo pessoal de 2009

A Pedra do Ingá foi tombada pelo Instituto do Patrimônio Histórico e Artístico Nacional - IPHAN e está registrada no Livro de Belas Artes e no Livro Histórico ${ }^{2}$ em 1944, apesar de ser um monumento ${ }^{3}$ arqueológico. Somente em 1996 teve um pequeno museu criado e, que permanece até os dias de hoje aberto para visitação. A comunidade ingaense herdou este sítio arqueológico enquanto patrimônio, e para isso incorpora de forma processual esta produção cultural de 
tempos passados, a sua dinâmica cultural contemporânea. As itacoatiaras do Ingá, por não serem meros objetos produzidos pelo homem, pois se firmaram no tempo, ganhando representatividade de um tempo passado, essa noção pode ser percebida pois,

"Esses bens, por sua vez, nem sempre possuem atributos estritamente utilitários. Em muitos casos, servem evidentemente a propósitos práticos, mas possuem, ao mesmo tempo, significados mágico-religiosos e sociais, constituindo-se em verdadeiras entidades, dotadas de espírito, personalidade, vontade, etc” (Gonçalves 2005:18).

Neste sentido, em paralelo ao reconhecimento institucional deste patrimônio, outras relações se estabeleceram entre as itacoatiaras e a comunidade do entorno da Pedra do Ingá. É possível encontrar relatos de moradores sobre suas experiências que envolvem 'mal-assombros', estórias de botijas, 'visagens'. No documentário 'Reino da Serra', produção resultante do curso de extensão em 'Produção de Documentário' da Universidade Estadual da Paraíba, em 2013, dirigido por Sinaldo Luna, com produção dos alunos do curso, aborda depoimentos de moradores da localidade, que relatam estórias de seus antepassados, 'dos mais velhos' como denominam os entrevistados, sobre um reinado encantado, que abarca desde a Pedra do Ingá até as proximidades de Itatuba, município que faz fronteira com Ingá.

Neste documentário é possível identificar a materialidade que advém das memórias herdadas da tradição oral desta comunidade. Uma das entrevistadas ao falar sobre os poderes sobrenaturais que envolvem não apenas a Pedra do Ingá, mas outras serras próximas, descreve que por vezes sente o cheiro de bolo assando, de carne e flor, que emana das pedras. Para ela, estas pedras pertencem a um reino encantado e que há muita vida e mistério em torno deles. Enquanto isso acontecer, como menciona outra entrevistada, a senhora Lindalva Ferreira da Silva "Papai dizia e os mais velhos tudo diz, que enquanto não desencantar os reinados encantado que tem o mundo não se acaba” (Reino da Serra 2013). 
Outro documentário é 'Nas paredes da pedra Encantada's dirigido por Cristiano Bastos e Leonardo Bomfim, em 2011, onde remontam o álbum 'Paêbirú', retornando o trajeto da capital João Pessoa, até a Pedra do Ingá com o artista Lula Cortês, refazendo suas memórias e experiências. $\mathrm{O}$ artista relata no documentário, para a produção da obra, houve uma apropriação dos mitos, recolheu lendas, e até encontrou objetos trabalhados (fazendo referência a objetos arqueológicos), para enfim extrair o máximo de magia para suas composições.

Se faz necessário ressaltar que as variadas narrativas que abordam as formas presentes nos grafismos da pedra, têm como foco o que pode ser visto na sua parte frontal, que abarca seu painel principal e as gravuras existentes no piso a frente deste painel, onde estão as figuras de maior destaque. Mas esse mesmo suporte, bem como outros muito 'próximos, possuem outras gravações, com formas e técnicas diferenciadas, que não merecem tanta atenção dos visitantes, locais ou não, no tocante a apreciação e criação de uma mítica própria. Essas gravações podem ser observadas abaixo (imagem 04).

Essas narrativas que envolvem um imaginário, em certo aspecto factual, pois para estes moradores, não se tratam apenas de lendas ou algo fictício, elas fazem parte das memórias de seus 'mais velhos' e que são passadas adiante, e vivenciadas por parte desses moradores, tornando-se assim, algo concreto e real. Para Vansina a "tradição pode ser definida, de fato, como um testemunho transmitido verbalmente de uma geração para outra. Quase em toda parte, a palavra tem um poder misterioso, pois palavras criam coisas" (2010:141). E dessa maneira, pode-se dizer que a importância desse patrimônio arqueológico, ganha sentido e significado a medida que "os objetos que compõem um patrimônio precisam encontrar ressonância junto a seu público" (Gonçalves 2005:19), e isso também deve ser levado em consideração no processo de patrimonialização dos bens culturais.

O processo de patrimonialização deve levar em consideração o trabalho etnográfico, buscando compreender o papel das memórias sociais que permeiam os bens culturais, e como esses bens 
são percebidos pelas comunidades contemporâneas que socializam num mesmo espaço. A noção de patrimônio cultural que surge deste trabalho intensifica o reconhecimento das identidades sociais, por meio das sociabilidades que são construídas entre comunidade, pesquisadores e instituições, bem como nas ações de preservação dos bens patrimoniais, pois "a presença da materialidade do espaço, reforça um sentimento de segurança e estabilidade" (Peixoto 2010:63), firmando assim, um empoderamento do patrimônio arqueológico nas memórias e identidades da comunidade que a salvaguarda.

Essa relação entre elementos da natureza e forças espirituais, segundo Cézar advém, conforme apontam estudos antropológicos, na própria escolha do suporte a ser trabalhado pelos indígenas, no caso de Ingá a rocha, de modo que nas pedras residem "entidades espirituais, as quais prepararam e proporcionam, até hoje, as condições de habitação da Terra por humanos. Assim, entende-se que esta manifestação está relacionada, em alguma medida, com as referidas crenças” (Cézar 2013:55). Percebe-se assim, que essas relações que talvez remetam as ações antepassadas indígenas, ainda permanecem, com novos sentidos, personagens, e representações, nas memórias e imaginário dos moradores locais.

A materialidade das inscrições da Pedra do Ingá neste sentido, tem garantido uma ideia de autenticidade histórica, e cria em torno desse bem patrimonial, elementos identitários que os tornam únicos para a comunidade, promovendo um investimento simbólico e estabelecendo um valor patrimonial ao seu bem cultural (Peixoto 2010; Bauman 2013). Seja resultante das memórias sociais, ou dos discursos dos agentes sociais envolvidos no processo institucional de patrimonialização, ambos são marcados pela sensação de certeza de que se trata de um bem cultural "insubstituível por memórias coletivas que encontram nos monumentos históricos que conformam a identidade dos lugares o referencial imagético das práticas e representações sociais" (Peixoto 2010:59). 
Este desejo de singularidade que permeia o bem cultural, estabelece pontos de tensão entre as ações que permeiam a conscientização e valoração do bem cultural, em contraponto a produção de consumo da cultura. Para Campos (2014:154) o problema desta questão está na centralização da experiência e da vivência do agora, de modo que, é preciso promover um reconhecimento e sentimento de pertença entre a comunidade e o patrimônio, para além de sua funcionalidade enquanto produto de uma vertente mercadológica.

Pensando nas contribuições positivas que o mercado pode gerar, principalmente no que tange elementos e fundos voltados para a preservação e conservação, pode-se dizer que, o patrimônio arqueológico de Ingá, possui certa divulgação que alcançou alguns canais midiáticos, e ainda é possível encontrar certa quantidade de informações em livros e publicações acadêmicas que auxiliam e legitimam no âmbito institucional para investimento em mais pesquisas e estudos, ou ainda na internet, seja em sites oficiais como IPHAN, como em blogs de moradores ingaenses, como em documentários.

Para que esta divulgação permanecesse ativa, o processo de patrimonialização deste sítio arqueológico exigiu para além de trabalhos científicos, seja no campo arqueológico, histórico ou turístico, mas principalmente das ações de reconhecimento por parte da população da cidade de Ingá. E este reconhecimento necessita constantemente, que as instituições de poder promovam e trabalhem em parceria, nas diferentes esferas, público e privado - municipal, estadual e federal, dando enfoque às atividades educacionais locais, para que as informações a respeito do bem cultural, de fato, passem a fazer parte da memória e identidade daquela comunidade.

Com a educação patrimonial alcançando a significância em outras esferas para além das atividades locais aos patrimônios, como o ensino básico nacional, é possível hoje encontrar em livros didáticos nacionais, referências à Pedra do Ingá, ampliando as potencialidades de reconhecimento e preservação deste sítio arqueológico. Apesar de afirmar em suas páginas virtuais o pouco apoio das instituições es- 
taduais e federais, o município de Ingá tem promovido ações de valorização do patrimônio arqueológico local, seja pelo símbolo (slogan) da própria prefeitura - nos ônibus e uniformes escolares, esculturas em praças, como também em atividades educativas para estudantes, não só alunos do município de Ingá, mas de outras regiões; no qual passou a chamar e divulgar o 'Parque Arqueológico das Itacoatiaras de Ingá-PB'.

O processo de reconhecimento e incorporação do patrimônio cultural com a comunidade de seu entorno, não escapa dos investimentos de cunho mercadológico das instituições que a administram, assim, o turismo se torna atividade inevitável e acarreta em benefícios econômicos para a cidade e seus moradores, possibilitando novos campos de trabalho e fonte de renda. Entre essas ações, a prefeitura de Ingá promoveu em 2015, no período das festas juninas, o 'Forró da Pedra', na área externa do Parque, atraindo novos visitantes, e inserindo a cidade no calendário festivo e turístico da região.

Kiyotani, Arruda \& Tavares sugerem o arqueoturismo para a Pedra do Ingá, de modo que para as autoras esse modelo seria "uma alternativa para diversificação da oferta, aumento da competitividade e fortalecimento da atividade em estados que enfrentam dificuldades nesse setor" (2015:01). Este tipo de turismo arqueológico envolveria "viagens motivadas pelo desejo de conhecer aspectos de culturas passadas" (2015:02), entretanto, as autoras já identificam e apontam as dificuldades que atualmente, também conhecemos, a pouca estrutura informativa e propriamente física que possibilite esse tipo de ação, assim como, percebe-se que "O déficit está presente não somente no sítio, mas também nos serviços de alimentação, hospedagem, transporte e lazer. Falta qualidade, pois os poucos estabelecimentos não dispõem de pessoal capacitado" (2015:11).

Apesar da importância do turismo, como elemento alternativo para a economia da população local, as ações de patrimonialização devem atuar de modo mais sistemáticas em questões que envolvem memórias, identidades, informações e conhecimentos para que, tal 
patrimônio seja percebido enquanto elemento significativo cultural, e parte da história e dos antepassados daquela comunidade, e não apenas como um fator econômico e mercadológico.

Entretanto é preciso focar mais os trabalhos científicos e nos diálogos entre pesquisadores e comunidade, pois conforme apresentaremos a seguir, Almeida pontua que "Há mais obras literárias escritas sobre esse fenômeno do que os de natureza acadêmica, mesmo assim inscritos na categoria da Arqueologia" (2009:15), outros autores que evidenciam este aspecto são Oliveira \& Menezes:

"Dentre as itacoatiaras paraibanas, o sítio arqueológico Pedra do Ingá é, sem dúvidas, o mais estudado por leigos e comunidade científica. Desde o século XVIII, este monumento gráfico é notificado e descrito em documentos" (Oliveira \& Menezes 2011:97).

\section{As itacoatiaras do agreste paraibano: do imaginário ao patrimônio arqueológico da Pedra do Ingá}

Nesse sentido, é possível encontrar obras sobre as itacoatiaras do Ingá que remetem ao campo da arqueologia, mas que por vezes envolvem elementos do ocultismo, astrologia, lendas, entre outros. Em contrapartida, ao buscar materiais produzidos por pesquisadores do campo arqueológico, encontra-se as análises da arqueóloga Gabriela Martin (2008), no qual para a pesquisadora as gravuras podem ter relação aos cultos de adoração às águas, ou ao próprio cosmos e elementos da natureza. Apesar de diferentes hipóteses elaboradas a essas figuras insculpidas, ainda têm seus significados desconhecido para os arqueólogos (Almeida 2009).

Pode-se dizer que este patrimônio provoca inúmeras percepções em torno de suas inscrições, conforme apontam Machado et al, que a

“[...] origem das inscrições é ainda desconhecida, mas produto de culturas indígenas que habitaram a região, e pela sua complexidade e mistério existem diferentes teorias e mitos que rodeiam a pedra e a origem das gravuras" (Machado et al 2012:177). 
Entre as hipóteses, encontramos a de Martins (2003), que acredita haver três correntes a respeito da autoria das gravações; a primeira volta-se para nativos da região de tempos remotos - índios Tupis ou Cariris, a segunda fala sobre uma cultura de outro continente - povos fenícios ou povos de continentes submersos, e a terceira fala da presença de mensagens de extraterrestres. Outra interpretação sobre as inscrições da Pedra do Ingá está nas relações entre as Itacoatiaras com o mito de Sumé,

"Alguns estudiosos correlacionam a Itacoatiara ao mito Sumé, enigma que abrange todo o continente americano. Sumé tem sido identificado como o apóstolo Tomé, que teria passado pelo Brasil e deixado suas pegadas em baixo relevo nas rochas" (Oliveira \& Menezes 2011:94).

Brito (2008) apresenta essas múltiplas interpretações, e elenca uma série de pesquisadores e suas suposições a respeito dos possíveis significados das itacoatiaras, além das mencionadas acima, também é possivel encontrar interpretações e suposições para as inscrições, desde estudos que comparam as inscrições de Ingá à desenhos da Ilha de Páscoa; ou a produções realizadas por civilizações extremamente antigas que tinham profunda relação astronômica (zodíaco); ou ainda, baseadas em cálculos matemáticos relacionada com o calendário lunar, entre outras hipóteses. Assim,

"Como vimos essa compilação ideogênico ora, apresentada, reunindo várias opiniões inspiradas na Pedra do Ingá, a priori, demonstra quanto ignoto e ambíguo é a expressão encerrada neste suntuoso monumento gráfico e só vem provar o quanto tênue é a fronteira entre a realidade e a ficção" (Brito 2008: 60).

Sobre as interpretações da Pedra do Ingá, Machado et al fazem um levantamento de alguns estudiosos que seguem uma vertente interpretativa próxima:

"Leon Clerot, Gabriela Martin, Josemir Camilo, Ladislau Netto, Teodoro Sampaio, Alfredo de Carvalho, Angione Costa, Vanderley de Brito são alguns dos estudiosos que acreditam que as gravuras 
de Ingá foram inscritas provavelmente pelos índios Cariris, ou por povos locais provenientes de outras regiões e possuem mais de 2.000 anos. Sua função para a comunidade indígena teria várias vertentes, a primeira delas, seria a simples representação da fauna e da flora local" (Machado et al 2012:178).

Entre os exemplos de interpretações, apresentados por Brito, pode-se destacar o do ufólogo Gilberto Santos que considera as inscrições de Ingá resultantes do "uso de raio laser, por seres interplanetários há milhares de anos" (2008:32), nesta linha interpretativa aparecem outros nomes como Eric von Däniken ${ }^{6}$, e o escritor e cronista paraibano Antônio V. Freire, no qual afirma em sua obra 'Revoltas e Repentes' de 1974, que as inscrições são "produto de civilizações alienígenas aportadas aqui em épocas remotíssimas” (Faria 1987:49).

Faria (1987) médico e curioso em assuntos relacionados à Pedra do Ingá dedicou seu tempo, cerca de trinta anos para elaborar sua própria teoria sobre os possíveis significados das inscrições itacoatiaras ingaenses. Para Faria, as inscrições seriam "desenhos estilizados das constelações zodiacais" (1987:68) e nesse sentido, ele cria correlações das diversas inscrições com diferentes constelações, seguindo uma perspectiva baseada no que o autor entende ser uma arqueoastronomia;

"Valemo-nos para nossa interpretação da probabilidade de alguns traços mais marcantes de algumas constelações terem sido registrados na itacoatiara, tais como a disposição, em arco, das estrelas em torno de Regulus, em Leão; a sinuosidade de Eridano; a forma retorcida de Escorpião; a paridade de Castor e Pollux em Gêmeos, etc." (Faria 1987:68).

Observando essa diversidade de interpretações e associações que surgem a partir das itacoatiaras do Ingá, identifica-se que "Nenhum sítio pré-histórico com pinturas ou gravuras rupestres, em todo Brasil, atraiu tantas pessoas dispostas a opinar e decifrar, como a Pedra do Ingá, cujo impacto visual impressiona leigos e desafia a arqueologia” (Martin 2008:298). Dessa maneira, a partir da análise semiótica 
peirceana é possível compreender que as inscrições enquanto elementos potenciais comunicadores, de certo modo 'convidam' o ser humano a promover possíveis significados e estabelecer diferentes representações.

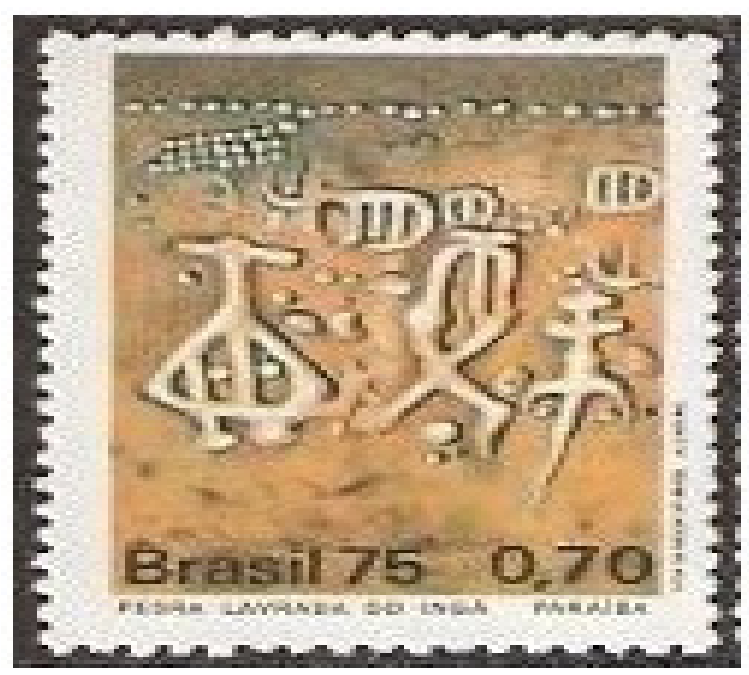

Imagem 05. Selo da série 'arqueologia brasileira' emitido em 1975, valor de C\$ 0,70. Fonte: Site Filatélica Penny Black (www.pennyblack.com.br/c-895-brasil-arqueologia-brasileira-pedra-lavada-do-inga).

Os signos ali trabalhados na pedra, digo signos porque atribui-se à eles a potencialidade de significado uma vez que são resultantes de uma produção humana em determinado contexto e temporalidade, permitem trocas simbólicas (Bourdieu 1983) via interlocução a partir de um processo de inteligibilidade, que se molda conforme os estratos de conhecimento e repertório cultural daquele que se coloca diante dessas imagens, variando suas semioses em diferentes possibilidades de significação.

Neste sentido, os significados que surgem conforme a necessidade de consumo, há aqueles voltados ao campo científico que envolvem pesquisas nos campos da arqueologia, antropologia, história, entre outros, assim como aqueles que permeiam o ocultismo, proposições 
históricas que beiram elementos míticos e de lendas, bem como o próprio imaginário que vai se transformando ao passo que é transmitido de geração à geração.

De qualquer modo, sejam pesquisadores do campo científico, ou curiosos e artistas, esses autores que abordam a Pedra do Ingá, sempre demonstram preocupações a respeito de sua preservação, a exemplo de Faria "esperamos que o vandalismo e a omissão governamental não continuem a conjurar a mutilação da Itacoatiara do Ingá" (1987:108), ou Brito "Por isso, urge que algo seja feito pela salvaguarda deste patrimônio da humanidade que, cada vez mais, inspira cuidados" (2008:27).

Neste sentido, as ações de preservação para com a Pedra do Ingá podem ser organizadas da seguinte maneira, nas décadas de 1940 e 1950 ocorreram os primeiros trabalhos sistemáticos de cunho arqueológico, sob orientação de José Anthero Pereira Júnior (Oliveira \& Menezes 2011). Já no início da década de 1960, foi realizada uma modelagem em gesso das inscrições (Brito 2008), e em 1999 o Estado da Paraíba, com autorização do IPHAN construiu um muro para a proteção deste Sítio Arqueológico. Sobre a construção do muro, a arqueóloga Gabriela Martin em entrevista ao Jornal do Commércio?, de 21 de setembro de 1999, relata sua preocupação com a descontextualização deste patrimônio com sua paisagem:

"Gabriela Martín explica que a Pedra do Ingá, distante 96 quilômetros da cidade de João Pessoa (PB), não pode ser vista como um monumento arqueológico isolado na paisagem. 'O entorno da pedra e o meio ambiente também fazem parte do sítio arqueológico', destaca. Ela questiona a eficácia do muro enquanto elemento de proteção da gravura rupestre mais famosa do país. 'Aquilo não impede nada, as pessoas continuarão entrando do mesmo jeito. $\mathrm{O}$ muro só tira a beleza e o encanto de um dos maiores monumentos do Brasil'" (Alves 1999:s/n).

Ainda na década de 1990, especialistas da Universidade de Lyon na França, em parceria com a Universidade Federal de Pernambuco, coordenada pelo arqueólogo francês Abel Pier, realizaram um mol- 
de de silicone das inscrições da Pedra do Ingá, possibilitando através desta modelagem a produção de réplicas com fibras de vidro, no qual uma das réplicas localiza-se no Departamento de História e Geografia da Universidade Federal de Campina Grande.

"O projeto de moldagem da Pedra do Ingá foi aprovado e supervisionado pela equipe de arqueólogos da UFPE, coordenado pela professora Gabriela Martin, a qual enviou estagiários e profissionais que, sob a coordenação do professor e engenheiro Abel Pier, da Universidade de Lyon, realizaram a confecção do molde” (Oliveira \& Menezes 2011:100).

As próprias pesquisas e estudos a respeito das possíveis interpretações servem como ações de preservação, de modo que mantém a memória e existência dessa produção cultural pré-histórica viva. E nestas ações pode-se encontrar informações que possibilitam direcionar para novos caminhos na compreensão desta produção, como os resquícios de pinturas (tinta a base de óxido de ferro) encontradas nos baixo-relevo das inscrições, por Luís Galdino na década de 1970 (Brito 2008), hoje não mais possível de serem percebidas a olho nu.

A Pedra do Ingá por ser um patrimônio arqueológico já institucionalizado, tombado pelo IPHAN, possui como se pode perceber, uma atenção maior, tanto na produção literária e científica, quanto na sua valoração enquanto bem cultural, como a divulgação deste patrimônio através da circulação de selos durante a década de 1970, conforme imagem 05.

Assim, o aspecto turístico também tem seus contornos de certa forma definidos, apesar da pouca infraestrutura e incentivos governamentais, mas a prática turística pode ser uma alternativa para a promoção do monumento, bem como um caminho para exigir mais investimentos e fiscalizações por parte da União.

A fama da Pedra estende-se pelo imaginário e místico, pelos estudos arqueológicos e científicos, pelos aspectos culturais. Neste contexto, Almeida apresenta em sua dissertação "uma releitura dos mitos, crenças, fé e religiosidade expressas” (2009:06) em obras literárias não científicas, que envolvem, por exemplo, o mito de São Tomé. 
Outro exemplo de como a Pedra do Ingá pode provocar influências simbólicas, temos na obra do disco 'Paêbirú', de Zé Ramalho e Lula Cortês, entre as faixas musicais, destaca-se aqui, a composição sobre a pedra do Ingá de 1974, intitulada 'Nas paredes da pedra encantada',

Quando as tiras do véu do pensamento

Desenrolam-se dentro de um espaço

Adquirem poderes quando eu passo

Pela terra solar dos cariris

Há uma pedra estranha que me diz

Que o vento se esconde num sopé

Que o fogo é escravo de um pajé

E que a água há de ser cristalizada

Nas paredes da pedra encantada

Os segredos talhados por Sumé [...]

Além desta faixa supracitada, neste álbum aparecem outras composições em homenagem à Pedra do Ingá, como 'Pedra Templo Animal', e 'Trilha de Sumé', estas canções ilustram bem a relação mística e que permeia o imaginário entre o patrimônio e os sujeitos.
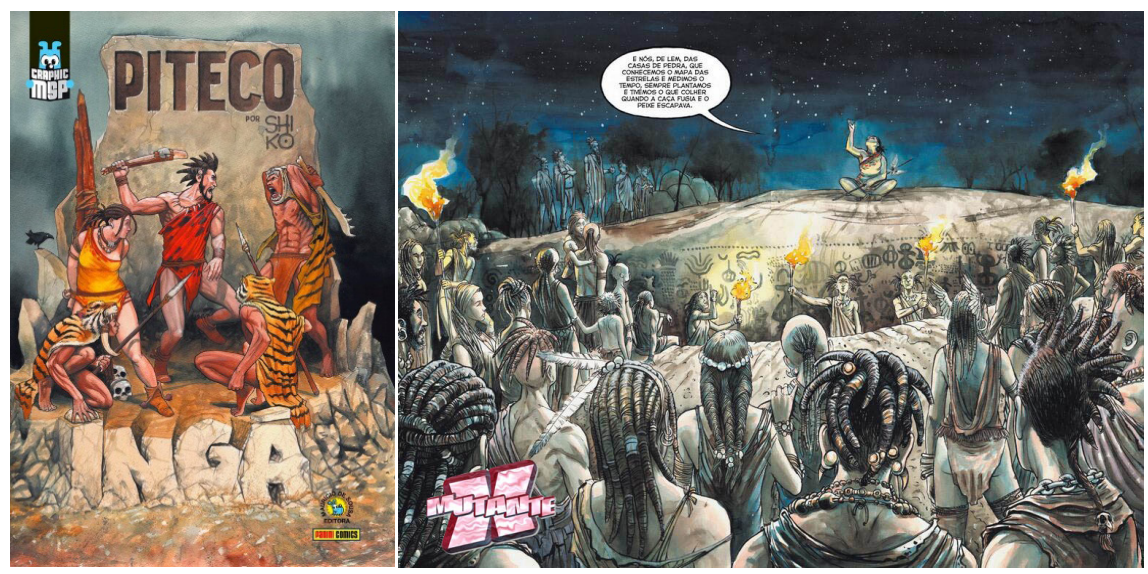

Imagem 06. Revista em Quadrinho Piteco - Ingá, do artista Shiko. Fonte: Site Raio X. (https://mutantexis.wordpress.com/2013/11/23/saido-do-forno-piteco-inga/). 

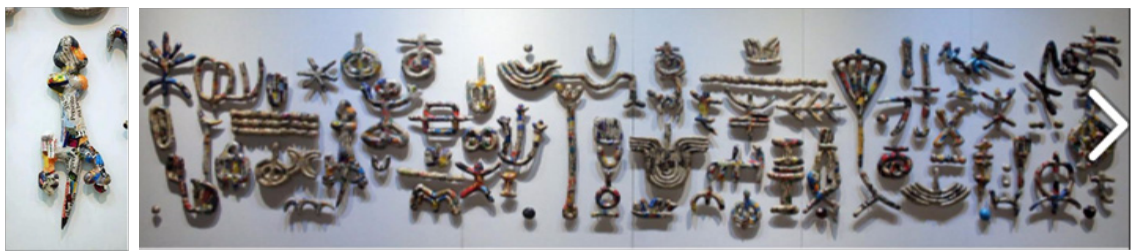

Imagem 07. Obra "Metalinguagem" de Luiz Barroso. Fonte: Portifólio Luiz Barroso. (https://issuu.com/luizbarrosopedras/docs/luiz_barroso_portf_lio_web).

Outras produções artísticas visuais que podemos citar são os quadrinhos do artista plástico paraibano Shiko, intitulado 'Piteco - Ingá' da coleção Graphic MSP, produzidos em 2013 pela editora Panini Livros, com quase oitenta páginas e faz referência ao personagem ' $\mathrm{Pi}$ teco’ da ‘Turma da Mônica', do quadrinista Maurício de Souza. Outra produção contemporânea é a obra de Luiz Barroso, intitulado 'Metalinguagem' e realizada em 2012, que são modelagens em papel machê e recortes de jornais e revistas moldados a partir das imagens das itacoatiaras do Ingá, com dimensões de 1 metro e 50 centímetros de altura por 5 metros de comprimento, conforme vemos nas imagens 06 e 07.

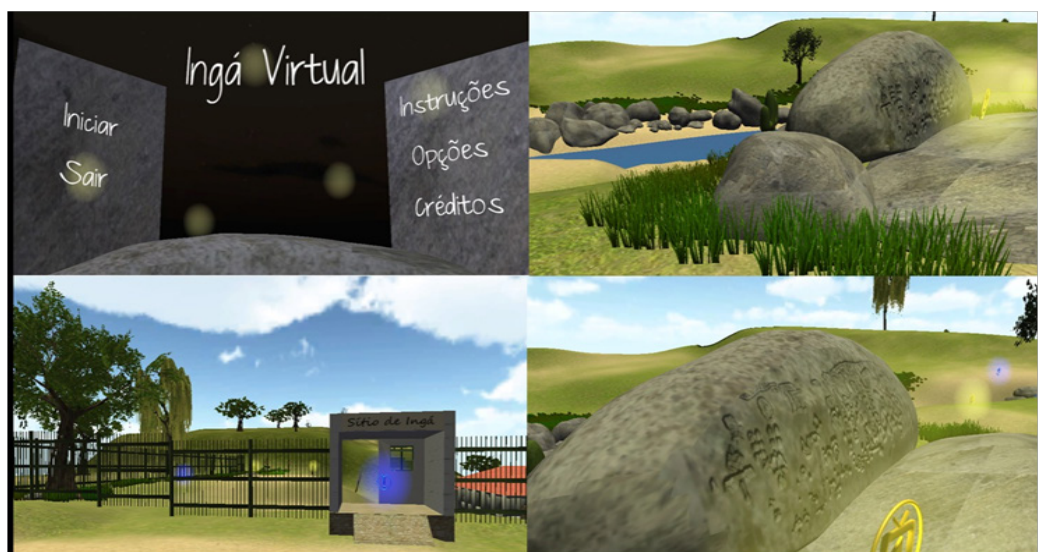

Imagem 08. Cenas da plataforma interativa do Sítio Arqueológico Virtual da Pedra do Ingá. Fonte: Site LabTEVE, 2016. (www.de.ufpb.br/ ${ }^{\sim}$ labteve/projetos/xpta_inga.html). 
Tanto a produção artística como o movimento literário que envolve proposições e o lúdico não deixa de legitimar uma potencial conscientização de preservação do bem patrimonial, ele acaba se tornando parte, das ações de conservação material e imaterial. Entretanto, se faz importante o aprofundamento nos estudos científicos, e da própria valoração do entorno paisagístico que caracterizam e contextualizam este patrimônio, para o desenvolvimento de ações educativas através das mediações entre os profissionais que ali estudam e a comunidade local, a fim de criar laços de pertencimento e a própria noção de cidadania.

\section{Considerações}

$\mathrm{O}$ artigo pretendeu apresentar diferentes formas de percepção e representação que um patrimônio pode provocar. Neste trabalho, a Pedra do Ingá aparece como um dos patrimônios arqueológicos brasileiros que causa curiosidades, proposições e suposições, e que perpassa o imaginário local, em diferentes gerações, tornando esses mitos numa materialidade própria da identidade desta comunidade, e parte do patrimônio cultural ingaense.

Considera-se que o imbricamento destes laços potencializa a conscientização para uma preservação contínua e duradoura, bem como, possibilitam o desenvolvimento de políticas culturais para ampliar a visibilidade. E com isso, o patrimônio além de representar e criar vínculos de pertencimento da comunidade pode servir como um agregador econômico, sustentável pelos próprios cidadãos, quanto estendendo a um público mais amplo, elevando seu patrimônio a patamares nacionais e internacionais, o que de certa maneira, vêm ocorrendo de forma incipiente em Ingá.

Dessa forma, o engajamento no campo científico se torna essencial para alcançar estes direcionamentos, para tanto o trabalho das instituições que gerenciam estes bens culturais devem manter sempre suas atenções voltadas para a promoção de projetos e nas ações de 
fiscalizações na manutenção e conservação dos mesmos. Assim, em 2013 o IPHAN lançou um projeto que investiria duzentos e cinquenta mil reais para realização de sondagem, prospecção, escavação e a conservação do painel da pedra do Ingá.

Sobre o projeto, intitulado 'Estudos Arqueológicos, Conservação e Socialização do Sítio Itacoatiaras do Ingá', coordenado pela arqueóloga Conceição Lage, houve um encontro em fevereiro de 2013 com pesquisadores, técnicos, autoridades e interessados para sua apresentação e discussão a respeito do projeto. Segundo o Boletim Informativo da Sociedade Paraibana de Arqueologia,

"O Plano também prevê a interação com a população local por meio de palestras e visitas monitoradas por técnicos para alunos da rede pública municipal, produção de um registro videográfico e a produção de uma publicação sob̉re a pesquisa” (2013:01).

Os resultados de tal projeto ainda não foram divulgados no site do IPHAN, o que não nos permite fazer possíveis análises desta ação neste momento, mas talvez durante a pesquisa de campo, possamos encontrar alguns indicativos sobre essa relação entre o patrimônio arqueológico de Ingá e sua comunidade. Entretanto, o projeto caracteriza-se dentro de um quadro geral, como uma significativa ação para a preservação do patrimônio, bem como, a aproximação da comunidade ingaense com a pedra do Ingá.

Neste mesmo ano, a dissertação de Cézar (2013) no mestrado profissional do IPHAN, discute algumas práticas desenvolvidas nas três esferas institucionais (municipal, estadual e federal) em relação às ações de preservação do sítio arqueológico de Ingá. $\mathrm{O}$ autor atenta para o número significativo de informações não científicas que permeiam este sítio, alertando que tais informações por vezes são mais acessadas e consumidas. Em sua pesquisa traça uma análise interdisciplinar, e apresenta registros imagéticos tanto da Pedra do Ingá e suas inscrições, como de artefatos encontrados na superfície do local. $\mathrm{O}$ objetivo de sua pesquisa é servir de suporte para ações de preservação e conservação à este patrimônio. 
Outro projeto desenvolvido para dar maior visibilidade à Pedra do Ingá, foi o 'Projeto Ingá Virtual' que estava inserido no 'Projeto Arqueologia Interativa', realizado pelo Laboratório de Tecnologias para o Ensino Virtual e Estatística - LabTEVE ${ }^{8}$, a partir do Programa de Laboratórios de Experimentação e Pesquisa em Tecnologias Audiovisuais, em parceria com outras universidades, como Universidade Federal de São Carlos (UFSCar), Universidade Federal do Pará (UFPA), Universidade do Estado de São Paulo (UNESP), entre outros (LabTEVE 2016).

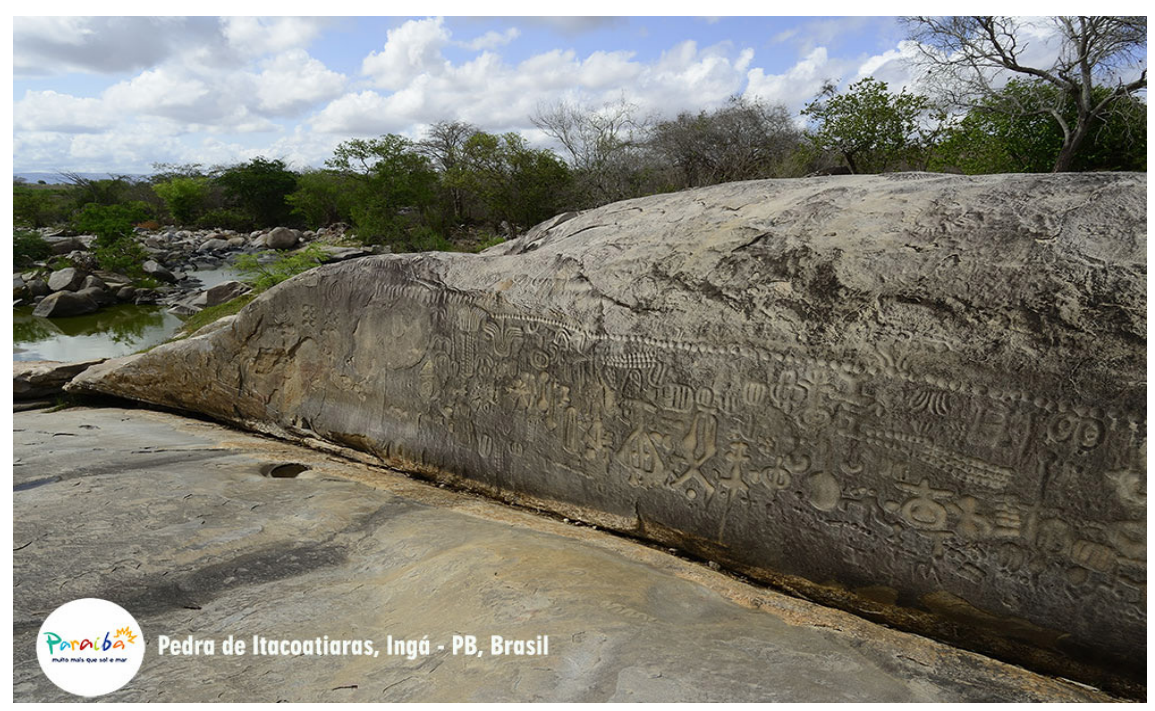

Imagem 09. Site Destino Paraíba. Fonte: www.destinoparaiba.pb.gov.br.

Este projeto buscou reunir informações históricas, arqueológicas e míticas, apresentando-as em um ambiente virtual multimídia e interativo. Assim é possível percorrer virtualmente a paisagem do entorno da Pedra do Ingá, bem como ela mesma, passando por estágios interativos, no qual o visitante virtual pode assistir a entrevistas e visualizar imagens reais do local, bem como ouvir os sons do ambiente, a exemplo do rio Bacamarte. Segundo Marques et al, 
"A proposta é agregar dados gerados a partir de coletas de artefatos arqueológicos a um único ambiente capaz de apresentar os objetos virtuais combinados a informações relevantes sobre a região. Através desta representação virtual, os visitantes poderão observar remotamente o monumento e detalhar aspectos de difícil observação no ambiente real, além de ter a possibilidade de acesso a dados e informações que, em sua grande maioria, não são disponibilizados em visitas presenciais ao local" (Marques et al 2009:01).

Entre o uso de recursos midiáticos, é possível encontrar websites institucionais a exemplo da página virtual do Governo do Estado da Paraíba, em que disponibiliza uma síntese informativa a respeito do sítio arqueológico de Ingá e ainda vídeos produzidos pela Secretaria de Turismo do governo do Estado da Paraíba, com a divulgação dos roteiros turísticos paraibanos, conforme imagem 09. No âmbito municipal, a página virtual da Prefeitura de Ingá disponibiliza matérias sobre atividades escolares que ocorreram no Parque Arqueológico de Ingá, bem como notícias relacionadas à este espaço cultural, e ainda chama a atenção para os benefícios de ações que atraiam o turismo, ampliem os potenciais econômicos do município e das dificuldades administrativas que enfrentam.

Seria interessante um diálogo mais ativo entre o IPHAN Paraíba, o Governo do Estado da Paraíba e a Prefeitura de Ingá em relação a ações de preservação, divulgação e pesquisa ao Parque Arqueológico das Itacoatiaras do Ingá. Mas as dificuldades são encontradas no próprio processo de elaboração de projetos junto ao IPHAN, como já identificam Kiyotani, Arruda \& Tavares

"Parece haver uma inaptidão de cumprir às exigências legais necessárias ao lidar com o patrimônio arqueológico. Os projetos apresentam-se falhos quanto à transdisciplinaridade, [...] ou têm foco notadamente científico, faltando o um projeto que contemple ambos os aspectos" (Kiyotani, Arruda \& Tavares 2015:09).

Nota-se assim, que as iniciativas de preservação, e fiscalização em termos de organização institucional, há certo negligenciamento por parte de todos os órgãos competentes, que acabam empurrando um 
contra o outro as responsabilidades, deixando de lado as ações de preservação e educação patrimonial da Pedra do Ingá.

"O governo do Estado apresentou um projeto relativamente grandioso de infraestrutura, mas sem obedecer às exigências legais, fato que poderia comprometer fortemente o patrimônio arqueológico, inclusive possíveis sítios ainda não descobertos. Impasses jurídicos quanto às questões de desapropriações e indenizações também colaboraram para a inviabilização de uma estruturação adequada, capaz de contemplar questões de desenvolvimento econômico, além da preservação e valorização do patrimônio arqueológico" (Kiyotani, Arruda \& Tavares 2015:13).

E apesar dos problemas institucionais, a participação da comunidade local e científica se colocam como um elemento importante para o funcionamento, manutenção e preservação desse monumento, uma vez que, essas ações atraem a atenção da sociedade de forma ampla, bem como permite denúncias, descobertas, reconhecimento e manutenção, mesmo que mínima, de ações que colaborem no processo de conservação e preservação de patrimônio arqueológico.

\section{Notas}

1 IBGE. Histórico do Município - Ingá. (www.cidades.ibge.gov.br/painel/historico.php?lang $=\&$ codmun $=250680$ \& search $=\mid$ inga).

2 (www.iphan.gov.br/ans/); acessar aba 'livro histórico', número de inscrição 234.

3 Para este artigo, adotamos a concepção Le Goff (1996), no qual monumentos são documentos, e documentos podem ser monumentos, pois quando institucionalizados pelas estruturas de poder passam a fazer parte do patrimônio cultural.

4 Documentário disponível em www.youtube.com/watch?v=wcQqT7JTD4g.

5 Documentário disponível em www.youtube.com/watch?v=5eQM6mIEjlA.

6 Escritor suíço, cujas teorias voltam-se para as influências extraterrestres sobre a cultura humana, desde a pré-história. Na década de 1970 escreveu o livro best-seller 'Eram os deuses astronautas' da Editora Melhoramentos. (http://files.comunidades.net/portaldoespirito/Eram_os_Deuses_Astronautas.pdf).

7 (www2.uol.com.br/JC/_1999/2109/cd2109o.htm).

8 No site do LabTEVE é possivel acessar a plataforma virtual interativa e visitar a Pedra do Ingá (virtual) e obter informações e imagens deste bem patrimonial. (www. de.ufpb.br/ $\sim$ labteve/projetos/xpta_inga.html). 


\section{Referências}

ALMEIDA, Maria Tereza. 2009. A pedra do Ingá: A reprodução do mito, a reprodução da fé, Brasil. Dissertação de Mestrado. João Pessoa: UFPB.

ALVES, Cleide. 1999. "Muralha esconde Pedra do Ingá". Jornal do Commércio. Recife. (www2.uol.com.br/JC/_1999/2109/cd2109o.htm; acesso em 18/02/2017).

BAUMAN, Zygmunt. 2013. A cultura no mundo líquido moderno. Rio de Janeiro: Zahar.

BOLETIM Informativo da Sociedade Paraibana de Arqueologia. 2013. Campina Grande, ano VIII, 83:82-83.

BOURDIEU, Pierre 1983. O campo científico. In ORTIZ, Renato (ed.): Pierre Bourdieu: Sociologia, pp.122-155. São Paulo: Ática.

BRITO, Vanderley. 2008. A Pedra do Ingá: Itacoatiaras na Paraíba. João Pessoa: RC Ed. . 2010. "A Pedra do Ingá sob uma perspectiva amerindiológica". Revista Tarairiu, 1(1):81-88.

CAMPOS, Elane Silva. 2014. "Bauman e a questão da Cultura". Revista Trama Interdisciplinar, 5(1):152-155.

CARVALHO, Paulo. 2006. Espécies arbóreas brasileiras. Brasília/ Colombo: Embrapa Informação Tecnológica/ Embrapa Florestas.

CÉZAR, Ted. 2013. Sitio Arqueológico Itacoatiaras do Rio Ingá: reflexões sobre preservação do patrimônio cultural e a documentação como instrumento para esta prática, Brasil. Dissertação Mestrado Profissional. Rio de Janeiro: IPHAN.

FARIA, Francisco. 1987. Os astrônomos pré-históricos do Ingá. São Paulo: IBRASA.

FIGUEIREDO, Vânia \& SILVA, Geane. 2009. "A importância da aula de campo na prática em geografia”. Trabalho apresentado no $10^{\circ}$ Encontro Nacional de Prática de Ensino de Geografia. Porto Alegre-RS.

GONCCALVES, José R. 2003. O Patrimônio como categoria de pensamento. In: ÁBREU, R. \& CHAGAS, M. (eds.): Memória e patrimônio: ensaios contemporâneos, pp. 21-29. Rio de Janeiro: DP\&A.

2005. "Ressonância, materialidade e subjetividade: as culturas como patrimônios”. Revista Horizontes Antropológicos, 11(23):15-36.

IBGE. 2017. Cidades - Paraíba. (www.cidades.ibge.gov.br/xtras/uf.php?lang=\&coduf $=25 \&$ search=paraiba; acesso em 15/01/2017).

. 2017. Itacoatiaras do Rio Ingá. (http://portal.iphan.gov.br/pagina/detalhes/824; acesso em 27/11/2016).

LE GOFF, Jacques. 1996. Memória e História. São Paulo: UNICAMP.

LOPES, Bruna \& LAGE, Maria C. 2013. "Estudos Arqueológicos: Conservação e socialização do sítio Itacoatiaras do Ingá-PB”. Revista IPHAN.

KIYOTANI; I., ARRUDA, L. \& TAVARES, A. 2015. "Arqueoturismo: o uso turístico das Itacoatiaras do Ingá/PB”, Trabalho apresentado no XII Seminário Anual ANPTUR - Associação Nacional de Pesquisa e Pós-Graduação em Turismo. Natal - RN. (www.anptur.org.br/anptur/anais/v.11/DCL1_pdf/6.pdf; acesso em $01 / 03 / 2017)$. 
MACHADO, Liliane et al. 2012. "Informação arqueológica de Ingá: preservação, acesso e uso a partir de um ambiente virtual”. Revista Informação $\mathcal{E}$ Sociedade, 22(ne):175-888.

MARTIN, Gabriela. 2008. Pré-história do Nordeste do Brasil. Recife: Editora Universitária da UFPE.

MARTINS, J.S. 2003. Itacoatiara do Ingá: prospecção de seu potencial turístico. Monografia de Conclusão de Curso. João Pessoa: IESP.

MARQUES, Marcos et al. 2009. "Representação do Sítio Arqueológico da Pedra de Ingá com Realidade Virtual". Trabalho apresentado no Workshop de Realidade Virtual e Aumentada, Santos - SP.

MILLER, Daniel. 2013. Trecos, troços e coisas: estudos antropológicos sobre a cultura. Rio de Janeiro: Zahar.

OLIVEIRA, Matusalém \& MENEZES, Washington. 2011. "Os ensinamentos de Sumé e a Tradição Itacoatiara no contexto da Pedra do Ingá: Pontes de contato com a narrativa bíblica do dilúvio”. Revista Hermenêutica, 11(2):93-111.

PEIXOTO, Fábio C. 2010. "A metrópole e a patrimonialização do território: a análise dos bairros de Santa Teresa". Revista Tamoios, 4(1):58-75.

VANSINA, Jean. 2010. A tradição oral e sua metodologia. In Ki-Zerbo, J. (ed.): História Geral da África, vol. 1., pp. 139-166. Brasília: Cortez / UNESCO.

\begin{abstract}
This article presents an analysis about some scientific, literary, and artistic productions that refer to the Itacoatiaras of Ingá. Thus, one can perceive through different perspectives, approaches and meanings regarding this archaeological patrimony. Understanding that the concept of cultural heritage should assume the sense that it allows for several significant dimensions, involving sociocultural and political issues, in their different forms, this allowed us to observe from different documents a diversity of interpretations and propositions, which while can create obstacles in relation to heritage education, or in relation to the scientific information already found. At the same time, they may find resonance in legends and local myths. But in any case, this heritage remains active in the memory of the local community and, potentially, of society through representations, creating elements that can collaborate in the process of preservation of this patrimony.
\end{abstract}

Keywords: Ingá stone; Patrimonialization; Patrimonial preservation; Memory.

Recebido em setembro de 2017. Aprovado em junho de 2018. 